\title{
Monitoring an Ocean Outfall using an AUV
}

\author{
Patrícia Ramos ${ }^{1,2}$, Nuno Cruz ${ }^{1}$, Aníbal Matos ${ }^{1}$, Mário V. Neves ${ }^{1}$, Fernando L. Pereira ${ }^{1}$ \\ ${ }^{1}$ Faculdade de Engenharia da Universidade do Porto \\ Rua Dr. Roberto Frias, 4200-465 Porto, Portugal \\ ${ }^{2}$ Instituto Superior de Contabilidade e Administração do Porto - Instituto Politécnico do Porto \\ Rua Padre Costa, 4465-111 S. Mamede de Infesta, Porto, Portugal \\ \{patricia, nacruz, anibal, mjneves, flp\}@fe.up.pt
}

\begin{abstract}
The wastewater plumes show to be very difficult to observed in detail. The several studies already conducted exhibit very complex and patchy structures both in vertical and horizontal sections.

It is not clear if this plume patchiness is due to physical processes or measurement limitations. Rapid tow-yo sampling is expected to reduce the time variability during and between transects. The AUVs may be a useful instrument to map and detect wastewater plumes.

This paper presents several prediction studies using time series files of actual in-situ measurements integrated in a near field model. The model predictions of the plume characteristics at the end of near field support the definition of the best sampling strategy for an AUV monitoring mission in a Portuguese west coast outfall.
\end{abstract}

\section{INTRODUCTION}

Several field studies using different types of techniques were already performed in order to map and detect sewage plumes. In all these studies, the very complex founded structures showed to be very difficult to identify with the classic picture of the buoyant plume. It is not proved yet if the patchiness of these structures is real and due to physical processes or measurement limitations. These studies are very important since, besides giving a better understanding of the plume behavior under certain conditions, can be used to be checked against prediction models.

Autonomous Underwater Vehicles (AUVs) have shown to be a very useful instrument in this case since they enable the efficient collection of data required to detect and map the plume. But the success of outfall monitoring missions using AUVs depends crucially on the efficiency of a sampling strategy.

This paper presents an exhaustive prediction study of the sewage plume of S. Jacinto outfall using time series files of actual in-situ measurements of flowrate, density profiles and current speed and direction. The model predictions of the plume characteristics at the end of near field, which include rise height and dilution, support an AUV sampling strategy for a monitoring mission.

The paper is organized as follows. In section II we describe the study area, giving some details about the S. Jacinto outfall and the seawater quality monitoring program that has already started in September 2000. In Section III, we give a short presentation of the Isurus AUV focussing on the monitoring operation aspects. In Section IV we present the in-situ measurements already collected in three campaigns conducted in September 2000, January and June 2001. Then in Section V, after a brief description of the data used in a plume behavior prediction model, the results are discussed. In section VI we present an AUV mission plan for monitoring the S. Jacinto outfall based on the obtained results. Finally, in Section VII we give some perspectives for future work.

\section{STUdy Site}

The bathymetry of the Aveiro coast and the mouth of its estuary, the oceanographic instrumentation sites and the S. Jacinto outfall are shown in Fig. 1.

This Portuguese outfall, in operation since May 2000, is presently discharging about $0.7 \mathrm{~m}^{3} / \mathrm{s}$ of mainly industrial wastewater. Its total length, including the diffuser, is $3378 \mathrm{~m}$ (first $3135 \mathrm{~m}$ with a diameter of $1600 \mathrm{~m}$ and last $243 \mathrm{~m}$ with a diameter of $1200 \mathrm{~m})$. The diffuser, consisting of 72 ports alternating in each side, $0.175 \mathrm{~m}$ diameter, is $332 \mathrm{~m}$ long. Presently only 20 of the 72 ports are working. These are discharging upwards at an angle of $30^{\circ}$ above the horizontal axis. The outfall has a bearing direction of $290^{\circ}$ and is discharging at a depth of about $15 \mathrm{~m}$.

A seawater quality monitoring program for this outfall has already started in September 2000. Its main purposes are to evaluate the background seawater quality both in the offshore and nearshore locations around the vicinity of the sea outfall and to follow the impacts of wastewater discharge in the area. In this monitoring program, measurement and sampling sessions are organized four times a year, being once per season. Three measurement sessions were already conducted in the following dates: September 2000, January 2001 and June 2001 .

The location of the offshore measurement and sampling stations established at different depths around the outfall is shown in Fig. 1. The letter A and a number, e.g. A2, identify the stations, except the reference one, which is indicated, with REF letters. A1 station is at $15 \mathrm{~m}$ depth, located almost above the end of the diffuser. At different distances from the diffuser but at the same depth are stations A3, A5, A6 and A7. In the outfall line are stations A2 and A4 respectively at $19 \mathrm{~m}$ and $13 \mathrm{~m}$ depth. The reference station, REF, is located 
at $37 \mathrm{~m}$ depth, at $6000 \mathrm{~m}$ of distance from the end of the outfall.

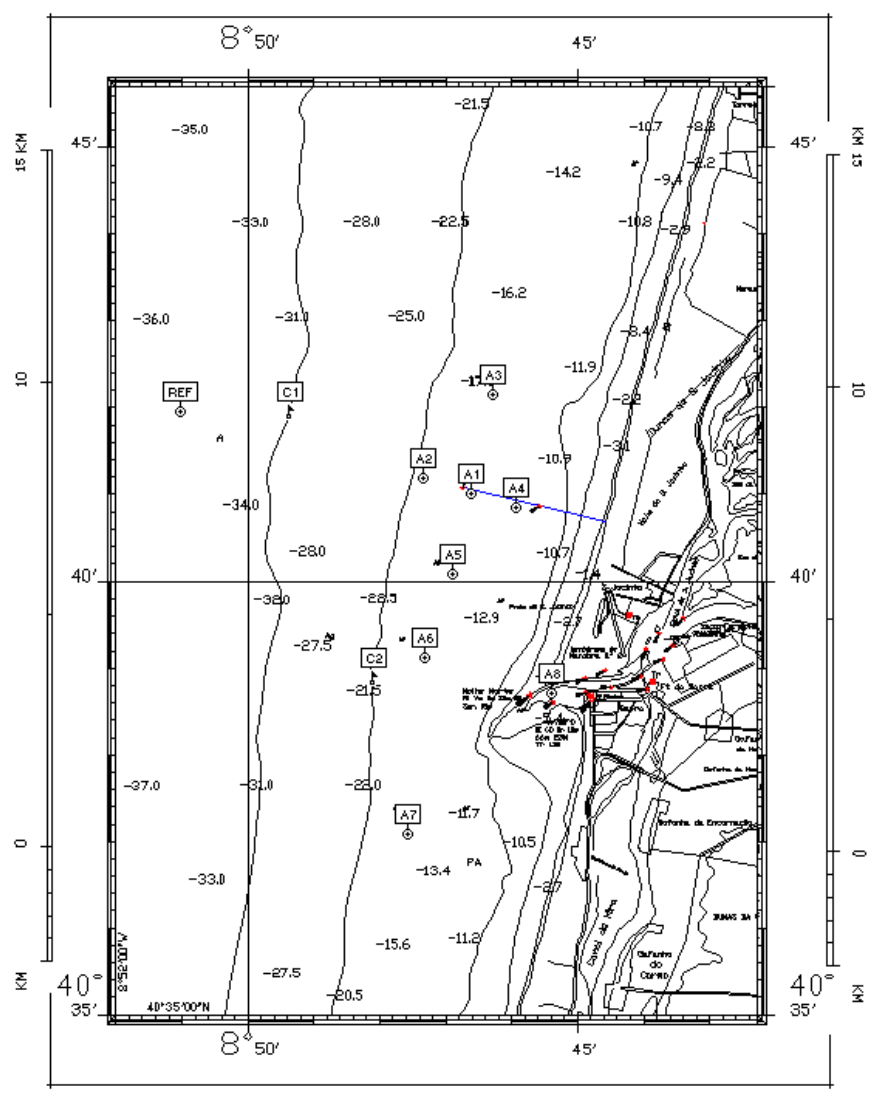

Fig. 1. Bathymetry, outfall and oceanographic instrumentation sites in the Aveiro coast.

\section{THE ISURUS AUV}

Isurus (Fig. 2) is a REMUS (Remote Environment Measuring UnitS) class AUV, built by the Woods Hole Oceanographic Institution, MA, USA, in 1997, [3].

The Systems and Underwater Technology Lab (LSTS) at the University of Porto has been operating and customizing it for the past 4 years [1]. Several missions were already performed with great success namely in the estuary of Minho River in the border between Portugal and Spain, and also in the Douro River [7].

These vehicles are low cost, lightweight AUVs specially designed for coastal waters monitoring (maximum depth of $200 \mathrm{~m}$ ). The reduced weight and dimensions makes them extremely easy to handle, requiring no special equipment for launching and recovery, such as winching systems.

Isurus has a diameter of $20 \mathrm{~cm}$ and is about 1.5 meters long, weighting about $30 \mathrm{~kg}$ in air. Its maximum forward speed is 4 knots, being however the best energy efficiency achieved at about 2 knots. At this velocity, the energy provided by a set of rechargeable Lithium-Ion batteries may last for over 20 hours (i.e., over 40 nautical miles).

Although small in size, this vehicle can accommodate a wide range of oceanographic sensors, according to mission objectives. For the missions mentioned above two specific sensors were integrated: a CTD (Conductivity, Temperature, Depth), OS200 model from Ocean Sensors, CA, USA, and an altimeter, from Imagenex, Canada but several successful tests have been performed in the past with ADCP (Acoustic Doppler Current Profiler), Optical BackScatter, Sidescan Sonar, etc.

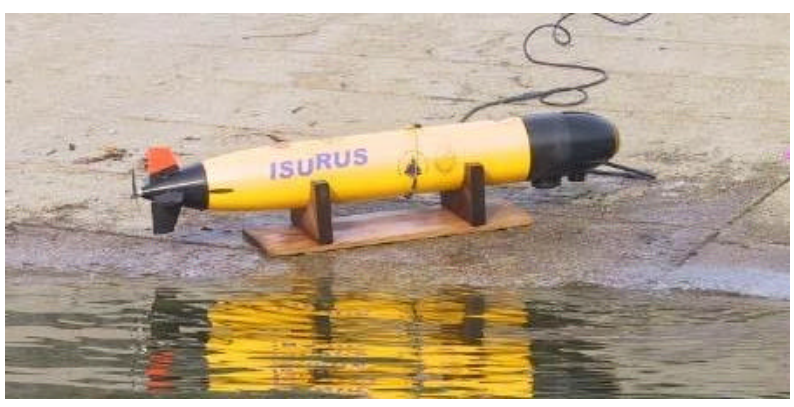

Fig. 2. The Isurus AUV.

\section{IN-SITU MEASUREMENTS}

In-situ measurements in the all stations were obtained for the three campaigns already conducted: September 2000, January 2001 and June 2001, with the exception of A7 which was performed in January due to bad weather. The locations of the measured stations were determined by DGPS (Differential Global Positioning System).

Data were collected from a sensor (OCEANSEVEN 316 manufactured by IDRONAUT-Italy) incorporated in a twelve bottle Rosette. This sensor measured, between the surface and the bottom, several physicochemical parameters, including pressure, temperature, salinity, dissolved oxygen, $\mathrm{pH}$ and turbidity. Real time sampling visualization of these parameters was accomplished with a RS232 Interface.

For the three campaigns, the vertical temperature and salinity profiles for the measured stations, are respectively in the first and second plots of Figs. 3, 5 and 6. The vertical temperature and salinity profiles of the January and June 2001 campaigns were obtained with a 0.2 meter resolution, while the September ones were obtained with 1 meter resolution. The seawater density profile presented in the third place of Figs. 3, 5 and 6, was computed from the temperature and salinity measurements.

The density difference over the water column for the three campaigns, in the stations that are able to better characterize the backgroundwaters and influence the plume behavior, which are A3, A5 and A6, is slightly different and varying along the seasons. 

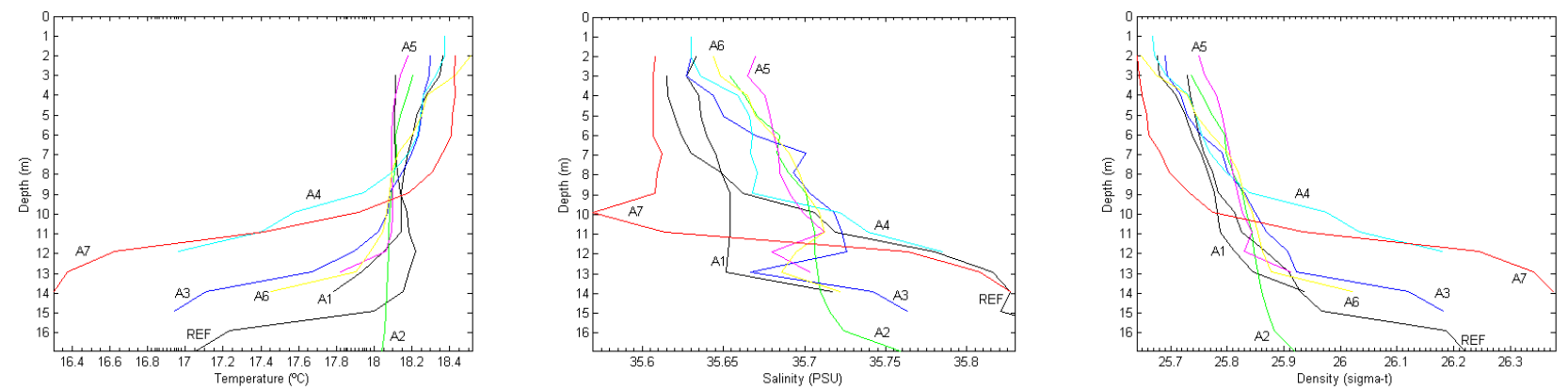

Fig. 3. Temperature, salinity and density profiles at all stations for the September 2000 campaign.

The maximum observed value was obtained in the January campaign and is about $1.8 \sigma_{\mathrm{t}}$-units. This density difference is mainly influence of the salinity difference, which reaches its maximum value, approximately $2.5 \mathrm{PSU}$ in A5 station. In the following seasonally campaigns the density difference decreases being approximately $1.2 \sigma_{\mathrm{t}^{-}}$-units in June and $0.5 \sigma_{\mathrm{t}^{-}}$ units in September. The significance of this is discussed in the next section, were we present the model results.

Additionally, measurements of currents were also obtained from 2 electromagnetic current meters moored at 17 and 27 meters depth and operating from January $17^{\text {th }}$ to April $5^{\text {th }}$, 2001. This equipment was set to record current speed and direction at twenty minutes intervals.

Its location in the study area at the $17 \mathrm{~m}$ and $27 \mathrm{~m}$ depth is identified in Fig. 1 respectively with $\mathrm{C} 2$ and $\mathrm{C} 1$ points. The stick plots of the currents measured at $\mathrm{C} 2$ point are shown in Fig. 4.

As expected, the stronger and predominant current directions are NNW and SSE, parallel to the local bathymetry. The stronger current velocities at the $17 \mathrm{~m}$ depth in the NNW and SSE directions, for the period above mentioned, were around respectively $0.7 \mathrm{~m} / \mathrm{s}$ and $0.5 \mathrm{~m} / \mathrm{s}$, being the average values much weaker.

Seawater samples at the different depths were also collected from the eleven bottles of the Rosette and properly stored in order to perform precise chemical and microbiological analysis.

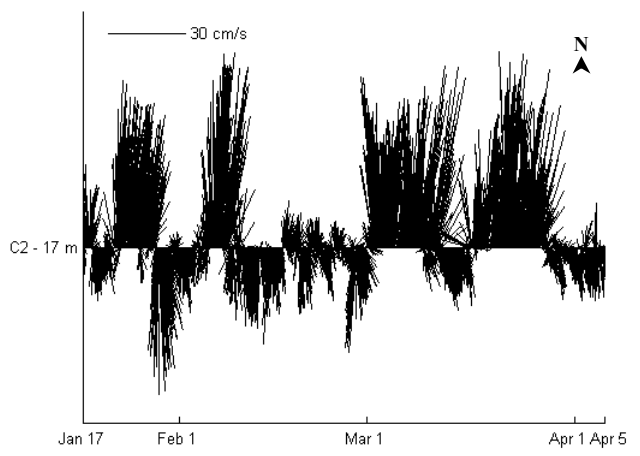

Fig. 4. Stick plots of currents at point $\mathrm{C} 2$ measured by an electromagnetic current meter between January $17^{\text {th }}$ and February $27^{\text {th }}, 2001$.

\section{Model Results}

The wastewater is mixed by physical, chemical and biological processes that occur over a wide range of length and time scales. The initial mixing zone, where intense turbulence generated by the buoyancy and momentum of the discharge occurs, is called the near field. This first zone ends where, due to density stratification, the plume stops rising, reaching a level of neutral buoyancy, starting to spread laterally.
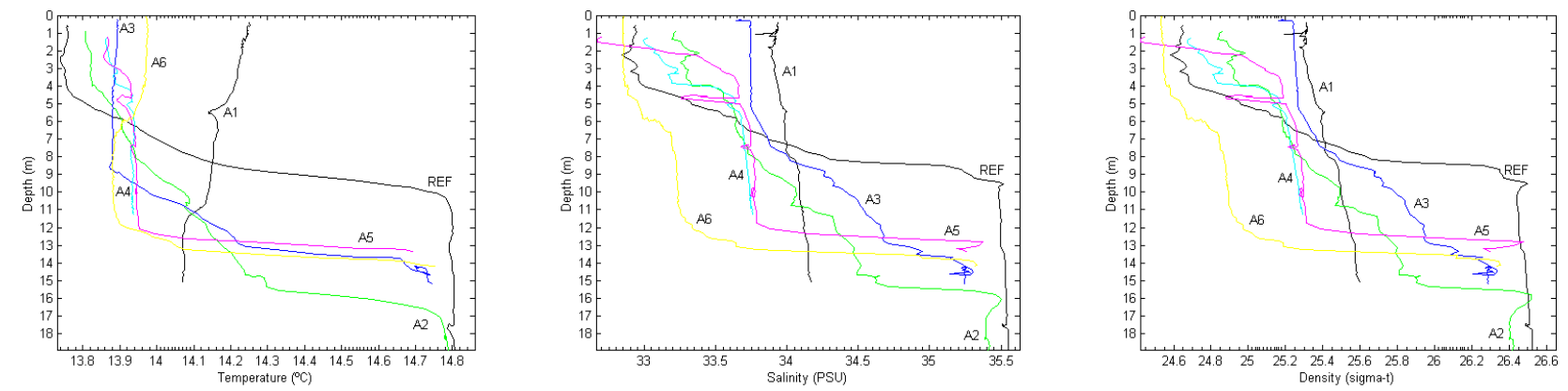

Fig. 5. Temperature, salinity and density profiles at all stations for the January 2001 campaign. 

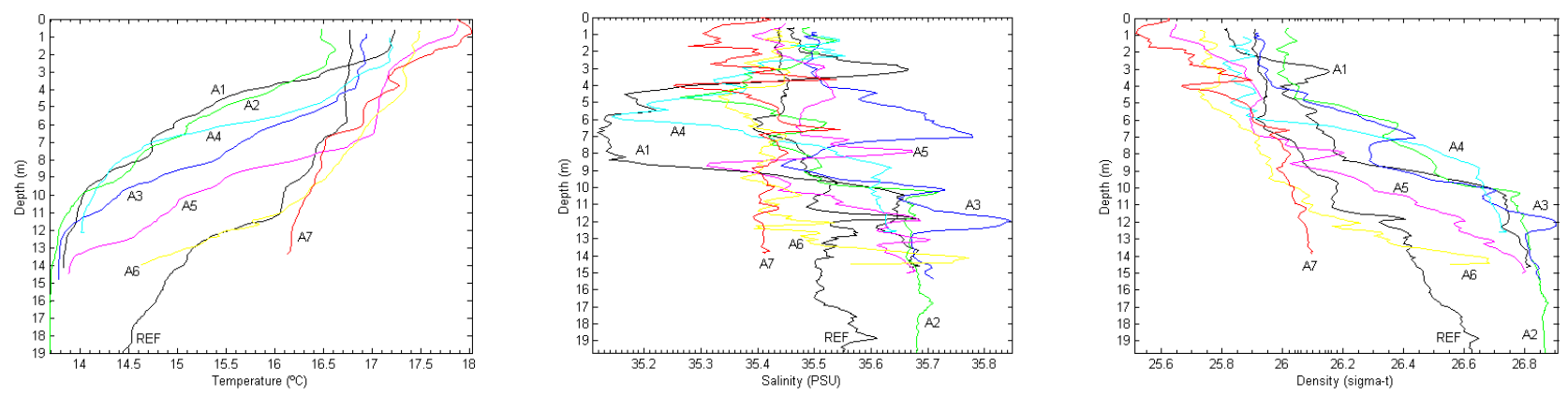

Fig. 6. Temperature, salinity and density profiles at all stations for the June 2001 campaign.

Then this established wastefield drifts with the ocean current and is diffused by oceanic turbulence in a region called the far field. The rate of mixing in the far field is much slower than in the near field.

In this study we only address the near field behavior of the plume. The model used to predict this behavior under steadysate conditions was RSB. This model is based on the experimental measurements of Roberts, Snyder and Baumgartner of multiport line diffusers in density-stratified currents of arbitrary direction [5]. It is a length scale model that uses semi-empirical formulations based on the relative magnitudes of the dominant length scales of the problem. The model predictions are the plume characteristics at the end of near field, which include dilution, rise height, thickness and length of the initial mixing zone.

This model was latter recoded by P. W. Roberts in order to incorporate long time series of oceanographic data, remaining the same principles, [6]. This latter model was designated by NRFIELD. This capability, particularly useful in this study, was actually one of the main reasons because it was chosen, since our main purpose was to predict the performance of the outfall under a range of conditions actually recorded in the field.

The input data for NRFIELD, consist of time series files of density profiles, currents and effluent flowrate that can have been measured in unequal time increments.

The density profiles of stations A3 and A5 were chosen to characterize the background waters of the three different seasons. A1, A2, and A4 profiles were excluded since these stations are too close to the diffuser and may naturally be influenced by it. The profiles of A6 and mostly A7 are very different from the ones in the remaining stations. The influence of increased tidal mixing or outflow of waters heated in the estuary over a tidal cycle may contribute to the elevated temperatures and reduced gradient. Specially in the January campaign, the reference station profile is quite different from the others, since the layer of cold and less saline water is considerably thicker for the shallow-water stations, and the deep layer below the thermocline, that begins at just $10 \mathrm{~m}$, is not evident at the other sites.

The currents from the $\mathrm{C} 2$ point shown in Fig. 4 were chosen for the NRFIELD simulations since its measurement depth is almost the same of the discharge. The flow rate data, obtained from the treatment plant in an 8-hour interval, were considered for the same time period of current, mainly because this is a quite good reasonable representation of the data conditions and makes density profiles the only parameter variable between different simulations. The flowrate data plot is shown in Fig. 7.

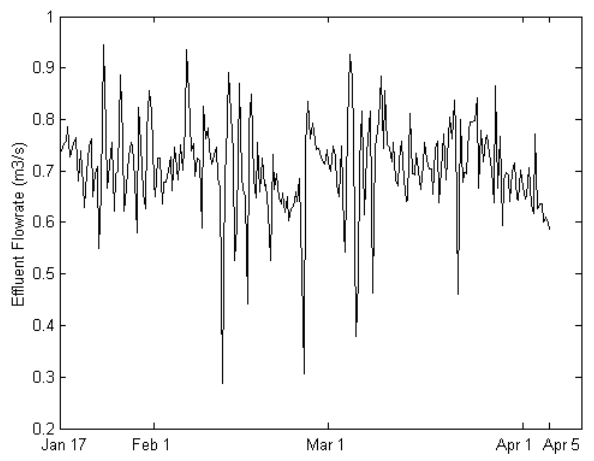

Fig. 7. Effluent flowrate between January $17^{\text {th }}$ and February $27^{\text {th }}$, 2001.

All these data were input into the model at twenty minutes intervals and long time series of predicted near field plume characteristics were generated. Note that in each step of A3 and $\mathrm{A} 5$ stations simulation, the same density profile was used for the three seasons.

Simultaneously, measured flow rate, density stratification, and current speed and direction should be preferentially used at each step of a model simulation, in order to predict the actual plume behavior during the time period considered. This was impossible to do in this study since we have no such data, even in the January campaign, but the main purpose was accomplished since we were able to perform simulations in a wide range of reasonable conditions for each season and certainly were considered the best and the worst situations. 

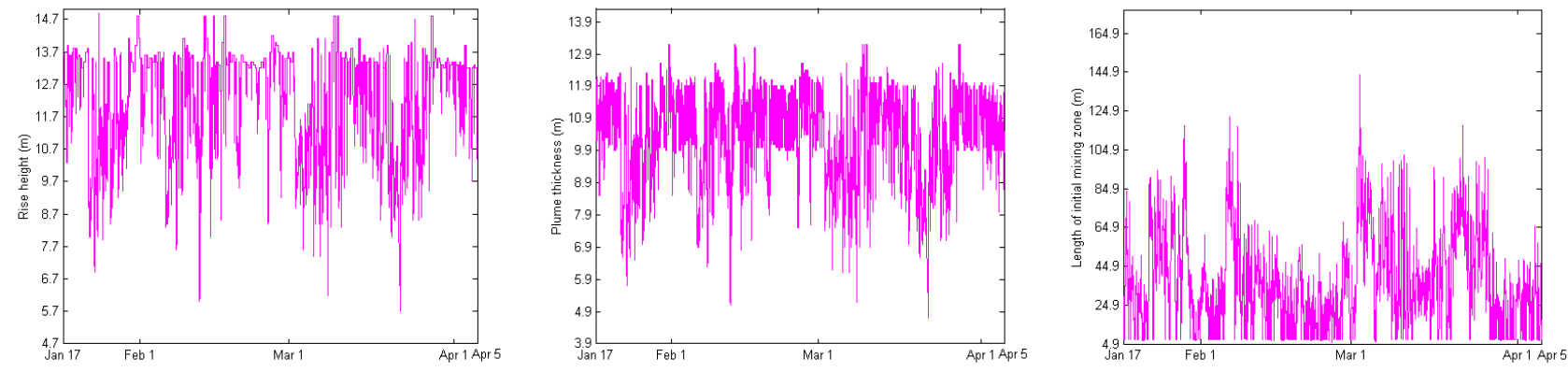

Fig. 8. Near field simulation results for A5 station of the January 2001 campaign.

Predicted time series of rise height, thickness, length of the initial mixing zone and dilution were obtained for each A3 and $\mathrm{A} 5$ season profiles using the $17 \mathrm{~m}$ current and the flow rate measured between January $17^{\text {th }}$ and February $27^{\text {th }}, 2001$

Since RSB assumes that ports are discharging horizontally from both sides of the diffuser, the port spacing was doubled because in this case the ports are alternated in each side. This approximation, done in order to preserve the total diffuser length and the discharge per unit diffuser length, is recommended in reference [8].

Some of the near field results, plotted in accordance with the station color (only for color printed copies), can be found in Figs. 8 and 9.

No significant difference was found in the simulation results of $\mathrm{A} 3$ and $\mathrm{A} 5$ profiles for the same campaign, but important differences were found between the three seasons.

The first plot of Fig. 8 illustrates that the plume predicted to be continuously submerged above the $7 \mathrm{~m}$ for the January simulations, even being most of the time very close to the surface. In the June simulations it was more frequently at the surface, but it was also found submerged above the $11.5 \mathrm{~m}$. The September results show the plume surfacing $100 \%$ of the time.

Consequently the plume thickness increases slightly in the June and September campaigns.
As is shown in the second plot of Fig. 8 this value ranges between 5.9 and $11.9 \mathrm{~m}$ in January while in June and September, with similar results, this value is not so restricted and is frequently between 11.2 and $13.2 \mathrm{~m}$. The height to the bottom (not showed) is always between 1.6 and $3.6 \mathrm{~m}$.

As it would be expected with the above results, the length of the near field increases slightly between January and September. Initial mixing in January occurs within the first $120 \mathrm{~m}$. This value is increased to $150 \mathrm{~m}$ in June and reaches its maximum around $190 \mathrm{~m}$ in the September month. The lowest dilutions occur in January when the plume is submerged. As usual the dilutions of surfacing plumes are higher and, in this case, they occur in September. The dilution plot for this month (Fig. 9) indicates maximum values around 1:340.

Density stratification over the water column demonstrated to play an important role in the plume behavior. This parameter controlled plume rise height and thickness, affecting dilution and the length of the near field. In general, the stratification required for submergence increases with increasing flow rate; it decreases with increasing current speed, being most sensitive to the current speed when the current flows perpendicular to the diffuser and least sensitive when it flows more nearly parallel [5].
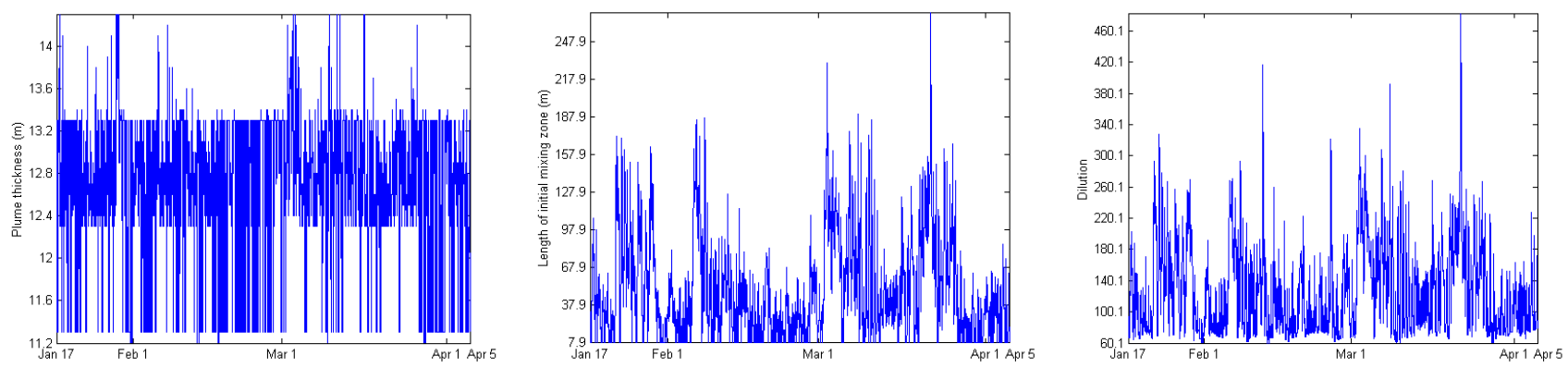

Fig. 9. Near field simulation results for A3 station of the September 2000 campaign. 


\section{MISSION PLAN}

Monitoring missions using the Isurus AUV are being prepared for the S. Jacinto outfall. Until now the seawater quality standards, in the stations considered, have been achieved but there is no real knowledge of the impacts of wastewater discharge in the area. We expect to be able to detect and map the plume using the CTD measurements of the missions that the vehicle will be able to perform in the vicinity of the outfall. If possible, the graphical representation of temperature and salinity on a T-S diagram with initial mixing lines between wastewater and ambient waters will be used to estimate plume dilution [2].

This large amount of simulations considering a wide range of oceanographic and flowrate conditions gave us a better idea of the plume behavior in this three times of the year. We can expect that the initial mixing zone length will always be less than $200 \mathrm{~m}$ and the height to the bottom will be around 2 $\mathrm{m}$, which are suitable operational conditions for Isurus.

Vertical sections, were the Isurus vehicle can perform yoyo shaped transects, are not particularly useful in this case of near field monitoring. With a $10^{\circ}$-dive angle the vehicle can perform minimum cycles of $150 \mathrm{~m}$ in yo-yos of $13 \mathrm{~m}$ amplitude. So, horizontal transects at different depths with a $3 \mathrm{~m}$ resolution in the first $250 \mathrm{~m}$ downstream seem to be a right choice for these specific conditions. The horizontal trajectories of $150 \mathrm{~m}$ long will be spaced of $50 \mathrm{~m}$.

The high frequency sampling of the CTD sensor will provide enough horizontal and, when necessary, vertical resolution for characterizing the dispersal of the outfall plume in reasonable spaced transects.

\section{FUTURE WORK}

Since outfall projects and risk assessment decisions are always based on modeled dilutions it is essential that predicted characteristics of wastewater plumes be checked against in situ measurements.

The sampling results of the Isurus vehicle can be easily compared with predictions of some commonly used near field mathematical models such as RSB [5], UM3 [8] and CORMIX [4] in order to evaluate its performance under the considered conditions.

During the Isurus mission, in addition to flowrate, simultaneous measurements of the oceanographic conditions will be collected, namely density and current velocity and direction over the all water column. These data will be integrated into the mentioned models, making the several assumptions they require. For example RSB and CORMIX models consider constant values of current speed and direction over the water column. RSB and UM3 allow input of the actual density profiles while in CORMIX the user must decide which profile is more suitable between four possibilities. The outputs of these models will then be compared with the sampled results of the Isurus AUV.

\section{REFERENCES}

[1] A. Matos, N. Cruz, A. Martins, F. L. Pereira, "Development and Implementation of a Low-Cost LBL Navigation System for an AUV", In: Proceedings of the MTS/IEEE Oceans'99, Seatle, USA.

[2] A. Petrenko, B. H. Jones, T. D. Dickey, "Shape and initial dilution of the Sand Island Hawaii sewage plume", Journal of Hydraulic Engineering, ASCE, 124(6), June 1998, pp. 565-571.

[3] C. von Alt, B. Allen, T. Austin and R. Stokey, "Remote Environmental Measuring Units", Proceedings of the Autonomous Underwater Vehicle's 94 Conference, Cambridge, MA, USA, July 1994, pp. 13-19.

[4] P. J. Akar, and G. H. Jirka, "CORMIX2: An expert system for hydrodynamic mixing zone analysis of conventional and toxic submerged multiport diffuser discharges", Technical Report, U. S. EPA, Environmental Research Laboratory, Athens, GA, EPA-600/3-91/073.

[5] P. J. W. Roberts, W. H. Snyder, D. J. Baumgartner, "Ocean Outfalls", Journal of Hydraulic Engineering, ASCE, 115(1), January 1989, pp. 1-70.

[6] P. J. W. Roberts, "Modeling Mamala Bay outfall plumes. I: Near Field", Journal of Hydraulic Engineering, ASCE, 125(6), June 1999, pp. 564-573.

[7] P. Ramos, M. V. Neves, N. Cruz, F. L. Pereira, “Outfall Monitoring using Autonomous Underwater Vehicles". In: Proceedings of MWWD2000 - Marine Waste Water Discharges International Conference, 2000, Genova, Italy.

[8] W. E. Frick, P. J. W. Roberts, L. R. Davis, J. Keyes, D. J. Baumgartner, K. P. George, "Dilution Models for Effluent Discharges, $4^{\text {th }}$ edition (Visual Plumes)", U. S. E.P.A., E. R. D., NERL, Standards and Applied Science Division, Office of Science and Technology, Athens, Georgia, November 2000. 